\title{
Field note from Tajikistan Compound disaster - A new humanitarian challenge?
}

\author{
Charles Kelly \\ Affiliate, AON Benfield Hazard Research Centre \\ University College London \\ disasterkelly@yahoo.com; 727342412ck@compuserve.com
}

\section{ABSTRACT}

During the winter of 2007-2008 the Central Asian country of Tajikistan experienced an unusually cold winter which led to shortages of electricity, water and heating as well as food losses and these impacts occurred at the same time as a combined with a drought, and dramatically increased food prices and increased food insecurity. These impacts were exacerbated by a lack of investment in the water, power and fuel supplies, health care and education systems since independence in 1991. This combination of events was termed a compound disaster. The note explores the conditions in Tajikistan which created the compound disaster, the humanitarian response and how this disaster became a neglected event. The concept of compound disaster has gained limited acceptance in Central Asia but may also be applicable elsewhere. The difficulty of identifying and responding to a compound disaster creates a particular challenge for humanitarian organisations if they are to be effective in reducing human suffering due to disasters.

\section{KEYWORDS}

Compound disaster, Central Asia region

\section{Introduction}

In early 2008, Tajikistan experienced an unusual combination of natural hazard events (drought, extreme prolonged cold), and economic shocks (dramatic increases in food, fuel and other prices) which harmed the welfare and threatened the lives of many residing in the country. Underlying these immediate and direct impacts was a long-term general reduction in the capacities of health, water, electrical, education and other social and real infrastructures to deliver basic needs (heat, medical care, potable water, etc), which exacerbated the impact of the hazards and shocks.

The combination of multiple hazard events, economic shocks and degraded infrastructures created a disaster which challenged both the existing models of disasters and the normal modes for providing humanitarian assistance. Because of the overlapping nature of factors contributing to the disaster it was hard for humanitarian assistance organisations and the Government of Tajikistan to recognize and define the emergence and evolution of the mixture of events 
which led to the disaster. This lack of clarity also created significant challenges in communicating the nature, extent and appropriate responses to the disaster, with a resulting slowing of the humanitarian response. Understanding the nature of a compound disaster is important in ensuring that the humanitarian community and affected governments are able identify and quickly respond to these types of disasters when they develop.

\section{Background}

Tajikistan is a mountainous country of 7 million people located in Central Asia, to the north of Afghanistan. The country is the poorest of the former Soviet Republics with a human development ranking of 127 out of 182 countries (United Nations Development Program, 2009). A civil war immediately after independence, a protracted period of recovery since official peace in 1997, and limited success in securing conventional development support have resulted in some human development indicators now being worse than before independence.

Although much of mountainous Tajikistan is not appropriate for conventional crop-and-orchard agriculture, agriculture is a major source of employment and food security, for a majority of the population. Land use is privatised but a tendency towards directed land use focusing on cotton production (a legacy of the Soviet period) has occurred at the expense of food crops such as wheat (a diet staple), or feed. However, even if all available land was used for food production, Tajikistan would remain reliant on imports to assure basic food security.

\section{The disaster of 2008}

The disaster of 2008 began in 2007. A sharp increase in food and fuel prices in the latter part of 2007 led to increased food insecurity, particularly in the rural areas of Tajikistan. Unusually cold weather in January and February 2008 damaged food in storage and in the ground, and probably contributed to livestock deaths, further aggravating rural food insecurity.

Even as unusually cold weather persisted in January and February 2008, electrical supplies, the major source of heating in urban areas, were cut back due to a dramatic reduction in production capacity and increased demand in Tajikistan as well as in neighbouring countries. Tajikistan was not the only country to be affected by the unusually cold weather, but seems to be the one country in Central Asia which came closest to a catastrophic failure of electrical supplies. The electrical supply situation was so poor that most industrial and commercial users were cut off from electrical supplies for several weeks, with a consequent impact on economic activity and incomes.

The reduced supplies of electricity led hospitals to discharged patients and reduce operations. Health clinics closed or cut back services for the same reason. The cold weather and a lack of heating led schools to stop classes as students and teachers could not work in sub-freezing buildings (although official policy was that the schools should not close because of cold weather).

Water supplies in urban and rural areas were reduced due to a combination of damage from the cold and irregular electrical supplies. Household-level hygiene decreased, due to a lack of water for personal hygiene and cleaning, a lack of electricity, poor heating and crowding to maximise 


\section{Charles Kelly}

the use of limited heating supplies. There is circumstantial evidence of an influenza-like outbreak during the height of the cold weather, although the event was not captured in official health statistics.

\section{Response}

The humanitarian response to the events of 2007 and 2008 was slow to evolve and of variable effectiveness. The response was delayed as the hazard events (drought, extremely cold weather), external shocks (rapid and dramatic increases in food, fuel and other costs) and degraded infrastructure, were a new and un-experienced combination of events for which assistance organisations were largely unprepared. Critical information about the emerging crisis was not easily available, as Tajikistan had no formal humanitarian warning system in early 2008 (development of such a system began in mid-2008), and there was a tendency not to disclose information which could reflect poorly on the government or individual agencies.

As it became clear that something was happening in early 2008, discussions occurred within the humanitarian community as to whether the crisis was due to the drought, price increases, or cold weather. In the case of the cold weather and related electrical supply problems, the crisis was not given much attention by the international community until homes and office operations in the capital of Dushanbe were threatened with a rumoured threat of a total cut-off of electricity.

There was eventual success in developing a common understanding within the humanitarian community in Tajikistan. A common view emerged that the disaster was one which went beyond just a food price crisis, increased food insecurity or severe cold weather. However, despite this understanding, humanitarian agencies remained largely wedded to a sector and single hazard-based response. These individual responses were not easily assembled into an integrated approach to managing the impacts of the various factors contributing to the compound disaster.

The government initially indicated that the cold weather and dramatically reduced capacity to provide electricity for heating, water and other basic needs was not a problem. In the end, persuasive interventions by a key donor led the government to recognise the severity of the cold weather and potential loss of electrical supplies as an emerging crisis which required an urgent response.

Overall, the 2008 disaster in Tajikistan presented a new type of crisis. The multiple events placed new and unusual demands on the government and humanitarian actors. Even as the understanding of the crisis increased, and gained the designation of being a compound disaster, the larger humanitarian community, and donors who fund humanitarian operations, remained skeptical that the events of 2008 really constituted a disaster which was different, and which required new approaches to assistance and funding.

It would have been possible to announce a set of disasters facing Tajikistan, such as a cold wave, food insecurity, electrical shortages, threatening epidemics, and economic collapse (among others). However, the consensus was that such a shotgun approach to defining the disasters facing Tajikistan would have confused assistance providers and allowed for cherry picking in 
the provision of assistance, that is, relief funding would be directed towards one disaster (e.g., the lack of water) while not another (e.g., possible epidemics).

\section{Conceptualizing compound disaster}

The easiest way to define a compound disaster is to consider the factors which contributed to the disastrous impact. In the case of Tajikistan, these included all of the following:

1. Multiple hazard (disaster) events, for instance: unusually cold weather, severe food insecurity, dramatic increases in prices, political instability, and disease outbreaks.

2. A failure of basic services, for instance: a near collapse of electrical and natural gas supplies, a significant reduction in health, water and education services.

3. Economic contraction, for instance: a reduction in economic activity, and the loss of income.

4. A lack of investment in the social and physical capital needed to address the causes of the disaster to a point where conditions which can be anticipated lead to a disaster, for instance: electrical and water systems in poor condition.

The compound disaster in Tajikistan was marked by a lack of defined and accepted early warning indicators and a difficulty in collecting timely and useful information. These characteristics were probably more representative of the uniqueness of the disaster in Tajikistan than of a compound disaster per se.

As experience was gained in dealing with compound disaster conditions in Tajikistan it was recognised that there were two differences from what might be called a multiple disaster event. First, there were accentuating (and possibly mitigating) links within and between each of the five sets of factors laid out above. For example, the lack of electricity led to health and hygiene problems, and reduced economic activity. Reduced economic activity reduced income available to urban residents to purchase food during a period of unusually high prices. Individuals with limited assets (a large part of Tajik society) faced difficult choices in deciding whether to purchase food, heating, water, health care or education for children. Eventually, the linked nature of the compound disaster was mapped out (see Figure 1), a process which made it easier for many to understand what was meant by the term compound disaster.

Second, it became clear that many of the conditions contributing to the compound disaster were rooted in the fourth factor noted above: a lack of investment in social and, particularly, physical capital. For instance, little investment had been made since 1991 in the electrical or water systems of the country. If investments had been sufficient to, at least, replace outdated equipment and conduct routine maintenance, the impact of the extreme, but not historically unusual, cold weather would have been significantly less.

Whether this lack of investment in basic services was due to a lack of funding, misdirected or mismanaged development assistance, poor policies, intentional under- funding, corruption, or a combination of these factors, probably needs to be decided on a case by case basis. But it was clear that many of the impacts of the compound disaster could have been avoided if the development process has been more successful in providing for basic needs on a sustainable basis. 
Fig 1. Tajikistan Disaster Mapping

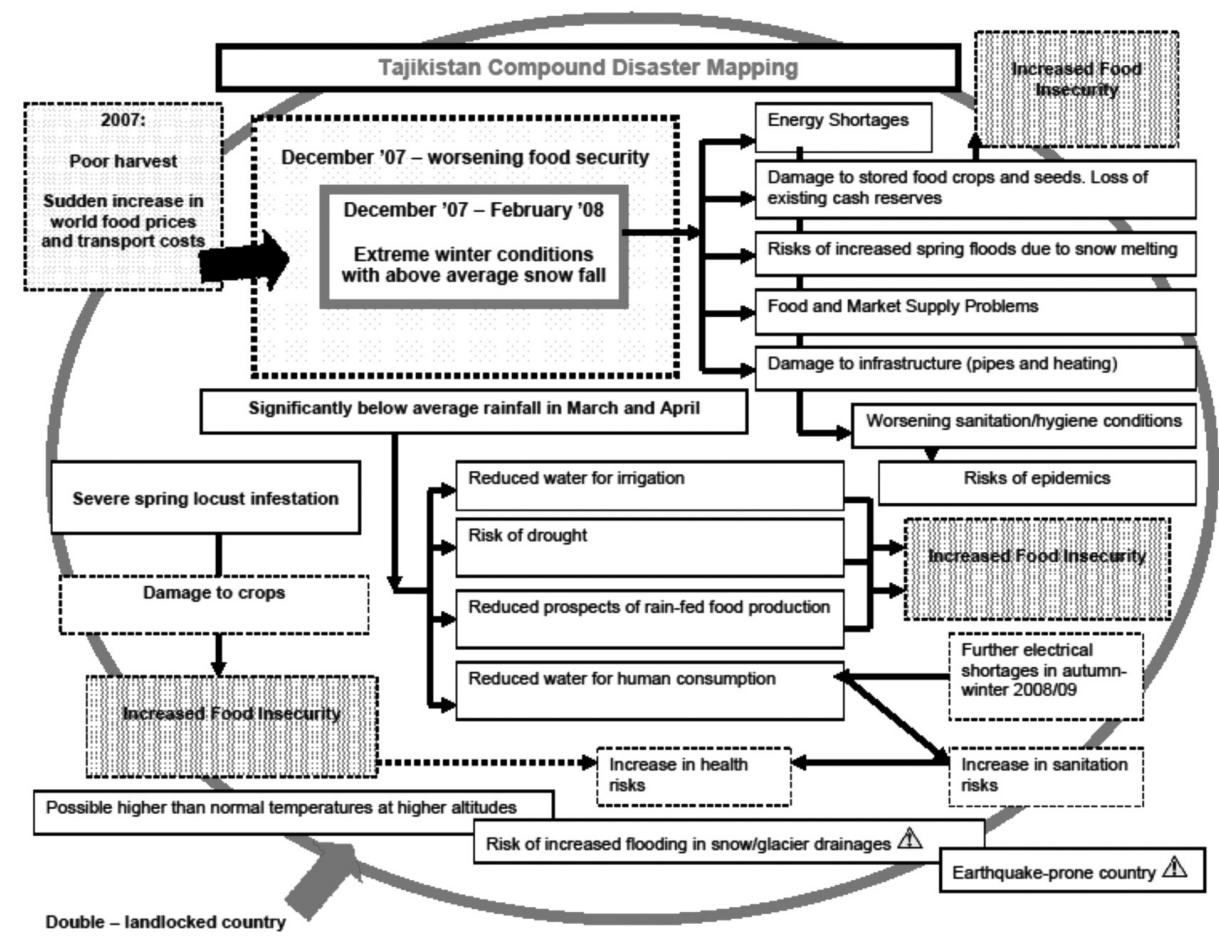

Source: Developed by Kashka Hyton, United Nations Office for the Coordination of Humanitarian Assistance

\section{A neglected disaster?}

The question arises whether the compound disaster fits into the category of a neglected disaster. The answer is yes.

The Tajik compound disaster certainly fell into the neglected category in its early stages. The drought, increased food prices and increased food insecurity of late 2007 were largely ignored. It was only through the strong advocacy of a few NGOs and international organisations that the emerging food security problem received attention in early 2008, concurrent with the onset of the extremely cold weather.

However, it was the threat of a near complete cut-off of electricity, which emerged in January and February 2008, that took concerns about the severity of the winter from a very limited number of humanitarian personnel to the predominant concern among the international community (and the government). What looked to be a neglected cold wave quickly became neither neglected nor ignored, at least until weather warmed in March and April.

Media coverage of the compound crisis was sparse but not absent. International media stories tended to call attention to the unusual event (the extreme cold weather) occurring in a distant place, with a leavening of comments about government policies which seemed to prioritise 
strategic infrastructure over basic needs. It is likely that media attention did have an impact of assistance funding (the launch of the Flash Appeal was timed to maximise media coverage) but as soon as the weather warmed, international media attention waned.

The U.N.'s Flash Appeal (OCHA, 2008) did result in assistance to Tajikistan, for cold weather, for the food shortages, to improve water supplies and to address a range of other impacts of the compound disaster. What followed this initial response were more extensive assessments of conditions in Tajikistan. These assessments created a broader and better documented understanding of the nature of the compound disaster as well as the complexity of addressing immediate needs and implementing a recovery which would limit such events in the future.

During the summer of 2008 an extensive consultation incorporating the assessment results was undertaken to develop a comprehensive response to the various aspects of the compound disaster. This response covered:

- On-going food security problems,

- Recovery from the damage caused by the severe winter, and

- Preparation for the forthcoming winter to prevent a recurrence of the negative humanitarian impacts.

The household, with its livelihood and disposable income, was chosen as the focus of an argument for assistance to prepare for the winter of 2008-2009. An argument was made that vulnerable families would face difficulties deciding how to divide limited funds on food, heating, securing safe water, education or health care during the coming winter. By reducing the impact of one problem, e.g., by providing cash to buy food, or stoves and subsidised fuel to reduce heating cost, the analysis suggested that the overall impact of the compound disaster during the coming winter could be reduced.

However, in the end, such a holistic focus on the household was not successful in convincing donors. Although cash and food aid were provided to address the food security problem, the other interventions proposed, from household winterisation to improving access to safe water, were not seen as immediately life saving and thus not fundable through existing humanitarian mechanisms.

The need for humanitarian assistance to address the continuing impacts of the compound disaster in 2008-2009, and to reduce the likelihood of a recurrence, was not so much neglected as simply rejected. In the end, the winter of 2008-2009 was much milder than a year earlier, and remittances from family members working abroad seem to have reduced vulnerability for many.

In the latter part of 2008 the United Nations Development Program commissioned an assessment looking at the various aspects of the compound crisis in Central Asia (De Martino, 2008). This Central Asia Regional Risk Assessment provided a basis for UN-donor and UNGovernment discussions about the impacts of the compound disaster in the region and how they could be addressed. For Tajikistan, these discussions led to the creation of a risk monitoring and warning system for the country and additional funds for recovery from the compound 


\section{Charles Kelly}

disaster. However, not much has been done to address the root causes for the compound disaster, with conditions in Tajikistan now commonly referred to as a compound crisis.

\section{Conclusion}

The conditions in Tajikistan in late 2007 and early 2008 were a new type of disaster, a compound disaster. This compound disaster differed from other types of disaster by

- The multiplicity of hazards and shocks involved,

- The links between these events,

- Weak underlying social and physical infrastructure,

- Poor warning and information availability,

-A lack of humanitarian experience in responding to such a combination of events, and

- Inflexibility in humanitarian funding mechanisms to respond to the unusual nature of the disaster.

The 2008 compound disaster became, in part, a neglected disaster because the approaches to address the impact of the disaster, as well as the steps needed to prevent a recurrence, fell outside the normal humanitarian funding mechanisms. Disaster assistance is not normally used to replace transformers, for pre-emptive winterisation to create one-warm-room in an apartment, to provide low cost/low maintenance water filters, or develop alternative energy sources for heating rural health clinics.

Climate change, natural hazards, economic crisis, and governance may combine in similar ways not only in the CIS and Central Asia, but also in parts of the Andes affected by severe winters to create new compound disasters. Such a concentration of factors, especially those related to climate, hazards, poverty, infrastructure and governance may also surface in warmer parts of the world. To ensure that disaster affected populations in such circumstances receive timely and appropriate humanitarian help it is critical quickly to identify the wide range of factors which contribute to a compound disaster.

\section{References}

DE MARTINO, L. 2008. Central Asia Regional Risk Assessment (draft). United Nations Development Program.

OCHA (United Nations Office of the Coordination of Humanitarian Assistance). 2008. Tajikistan Compound Crises Flash Appeal 2008. http://ochaonline.un.org/humanitarianappeal/webpage. asp?Page=1657. Date of Access: 12 Nov. 2009; revision 8 May 2008, http://ochaonline.un.org/ HUMANITARIANAPPEAL/webpage.asp?Page=1664 Date of Access: 22 Jan 2010.

UNITED NATIONS DEVELOPMENT PROGRAM. 2009. Human Development Report 2009. http://hdrstats.undp.org/en/countries/data_sheets/cty_ds_TJK.html. Date of Access: 11 Nov. 2009.

Note

I. An earlier version of this paper was presented at the World Conference of Humanitarian Studies 2009, 4-7 February 2009, Groningen, The Netherlands. 